\title{
Commentary: Psychological Science's Aversion to the Null
}

\author{
Jose D. Perezgonzalez ${ }^{1 *}$, Dolores Frías-Navarro ${ }^{2}$ and Juan Pascual-Llobell ${ }^{2}$ \\ ${ }^{1}$ Business School, Massey University, Palmerston North, New Zealand, ${ }^{2}$ Department of Methodology of the Behavioral \\ Sciences, Universitat de València, Valencia, Spain
}

Keywords: data testing, hypothesis testing, null hypothesis significance testing, effect size, falsificationism, statistics

\section{A commentary on}

\section{Psychological Science's Aversion to the Null}

by Heene, M., and Ferguson, C. J. (2017). Psychological Science under Scrutiny: Recent Challenges and Proposed Solutions, eds S. O. Lilienfeld and I. D. Waldman (Chichester: John Wiley \& Sons), 34-52.

Heene and Ferguson (2017) contributed important epistemological, ethical and didactical ideas to the debate on null hypothesis significance testing, chief among them ideas about falsificationism, statistical power, dubious statistical practices, and publication bias. Important as those contributions are, the authors do not fully resolve four confusions which we would like to clarify.

One confusion is equating the null hypothesis $\left(\mathrm{H}_{0}\right)$ with randomness when "chance" actually resides in the sample. We can, indeed, read three different instances of randomness in the text: associated with the sample on pages 36 (trial performance) and 37; associated with the alternative hypothesis $\left(\mathrm{H}_{\mathrm{A}}\right)$ on page 41 ("less likely to observe mean differences...far off the true... mean difference of $0.7^{\prime}$ ); and associated with $\mathrm{H}_{0}$ throughout the text, starting on page 36 . In reality, $\mathrm{H}_{0}$ simply claims a population non-effect $\left(\mathrm{H}_{0}: \Delta=0\right)$ while $\mathrm{H}_{\mathrm{A}}$ claims a constant effect (e.g., $\mathrm{H}_{\mathrm{A}}: \Delta$ $=0.7$ ), their corresponding distributions assuming random sampling variation in both cases. It is in the (random) sample where "chance" resides, as by chance we may pick a sample which shows a given effect (e.g., $\delta=0.3$ ) when the true effect in the population is either " 0 " $\left(\mathrm{H}_{0}\right)$ or " 0.7 " $\left(\mathrm{H}_{\mathrm{A}}\right)$. Frequentist tests only assess the probability of getting the observed sample effect under $\mathrm{H}_{0}$ while Bayesian statistics also assesses the probability of such effect under $\mathrm{H}_{\mathrm{A}}$ (e.g., Rouder et al., 2009). Therefore, the $p$-value does not inform about a hypothesis of chance but about the probability of the data under $\mathrm{H}_{0}$ (Fisher, 1954).

A second issue confuses power with missing true effects, something explicitly expressed on page 42 but also suggested when discussing sample sizes throughout the text (p. 36 onwards). The underlying argument is that larger sample sizes allow for achieving statistical significance so that a true effect may not be missed-something which is, at the same time, portrayed as unethical, e.g., p. 36, and ludicrous, e.g., p. 44. In reality, "we cannot manipulate population effect sizes" (p. 41 ), as they are deemed constant in the population (e.g., $\mathrm{H}_{\mathrm{A}}: \Delta=0.7$ ), and a significant result at $50 \%$ power will not be missed at $80 \%$ power. As Heene and Ferguson's Figures 3.1A,C show, power simply moves the goalposts on the real line, reducing the Type II error $(\beta)$, while the larger sample size also reduces the standard error. By moving the goalposts, smaller (by chance) sample effects get associated with $\mathrm{H}_{\mathrm{A}}$, which is a correct association as long as there is a true population effect. Thus, power is there not to prevent missing effects due to small sample sizes but to be able to justify whether we could plausibly accept $\mathrm{H}_{0}$ when results are not significant (Neyman, 1955; Cohen, 1988). 
A third issue is about falsificationism (pp. 35-37), which the authors argue cannot happen in psychology because we never accept $\mathrm{H}_{0}$, only reject it or fail to reject it. In reality, frequentist tests are logically based on modus tollens, the valid argument form for the falsification of statements (Perezgonzalez, 2017a). $\mathrm{H}_{0}$ is simply the contrapositive of our research hypothesis, and denying $\mathrm{H}_{0}$ allows us to affirm the latter. Therefore, frequentist tests are eminently falsificationist, attempting to disprove $\mathrm{H}_{0}$ via reductio arguments ( $p, \alpha$; Mayo, 2017). Indeed, $\mathrm{H}_{0}$ does not even need to be "zero" in the population: We could perfectly substitute the actual value of our $\mathrm{H}_{\mathrm{A}}$, so that we may prove the theory false with a significant result (the "strong" test purported by Meehl, 1997).

A fourth issue is whether we always need to be in the position of accepting $\mathrm{H}_{0}$ (something argued on pages 36-37). This is not necessarily so. Just testing $\mathrm{H}_{0}$ as for rejecting it is suitable when we are only interested in learning about our research hypothesis (e.g., does the treatment have an effect?-Perezgonzalez, 2016). In such context, $\mathrm{H}_{0}$ provides a precise statistical hypothesis for carrying out the test and, because the actual parameter $(\Delta)$ is unknown, it only provides informative value via its rejection (Fisher, 1954), $\mathrm{H}_{0}$ acting merely as a "straw man" (Cortina and Dunlap, 1997). This testing procedure was not only developed in the context of small samples (Fisher, 1954) but the lack of a specific $\mathrm{H}_{\mathrm{A}}$ precludes the control of Type II errors and of power. (A way forward would be to assess the effects warranted under $\mathrm{H}_{0}$ - Mayo and Spanos, 2006-or to control sample size via a sensitiveness analysis-Perezgonzalez, 2017b).

If we wish to be able to accept $\mathrm{H}_{0}$, then we are stating that we are also interested in the potential demise of our intervention

\section{REFERENCES}

Cohen, J. (1988). Statistical Power Analysis for the Behavioral Sciences, 2nd Edn. New York, NY: Psychology Press.

Cortina, J. M., and Dunlap, W. P. (1997). On the logic and purpose of significance testing. Psychol. Methods 2, 161-172. doi: 10.1037/1082-989X.2.2.161

Fisher, R. A. (1954). Statistical Methods for Research Workers, 12th Edn. Edinburgh: Oliver and Boyd.

Gelman, A., Carlin, J. B., Stern, H. S., Dunson, D. B., Vehtari, A., and Rubin, D. B. (2013). Bayesian Data Analysis, 3rd Edn. Boca Raton, FL: CRC Press.

Heene, M., and Ferguson, C. J. (2017). "Psychological science's aversion to the null, and why many of the things you think are true, aren't," in Psychological Science under Scrutiny: Recent Challenges and Proposed Solutions, eds S. O. Lilienfeld and I. D. Waldman (Chichester: John Wiley \& Sons), 34-52.

Jeffreys, H. (1939). Theory of Probability. Oxford: Clarendon Press.

Jeffreys, H. (1961). Theory of Probability, 3rd Edn. Oxford: Clarendon Press.

Mayo, D. G. (2017). If you're Seeing Limb-Sawing in p-Value Logic, You're Sawing Off the Limbs of Reductio Arguments [Web log post]. Available online at: https://errorstatistics.com/2017/04/15/if-youre-seeing-limb-sawingin-p-value-logic-youre-sawing-off-the-limbs-of-reductio-arguments/.

Mayo, D. G., and Spanos, A. (2006). Severe testing as a basic concept in a Neyman-Pearson philosophy of induction. Br. J. Philos. Sci. 57, 323-357. doi: 10.1093/bjps/axl003

Meehl, P.E. (1997). "The problem is epistemology, not statistics: replace significance tests by confidence intervals and quantify accuracy of risky numerical predictions," in What If There Were No Significance Tests? eds L. L. Harlow, S. A. Mulaik, and J. H. Steiger (Mahwah: Erlbaum), 393-425. (i.e., if the treatment has no effect, we want to make sure it is akin to placebo; Perezgonzalez, 2016). This testing seems similar to Fisher's, but it requires active control of the severity with which the alternative hypothesis is to be tested (ideally, $\geq 80 \%$ power; Neyman, 1955; Cohen, 1988). Such control necessarily means more information-a precise alternative hypothesis (e.g., $\mathrm{H}_{\mathrm{A}}: \mu_{1}-\mu_{2}=0.7$, vs. $\mathrm{H}_{0}: \mu_{1}-\mu_{2}=0$ ) and a specified Type II error for $\mathrm{H}_{\mathrm{A}}$ (e.g., $\beta=0.20$ )- so that the power of the test can be managed (given $\alpha, \beta$, and $N$ ). This approach not only allows for accepting $\mathrm{H}_{0}$ but also illustrates that power is only relevant for such purpose, not for rejecting $\mathrm{H}_{0}$. Such approach, and similar ones, have also been available since Fisher's tests of significance (e.g., Neyman and Pearson, 1928; Jeffreys, 1939).

As final note, frequentist approaches only deal with the probability of data under $\mathrm{H}_{0} \quad\left[\mathrm{p}\left(\mathrm{D} \mid \mathrm{H}_{0}\right)\right]$. If we want to say anything about the (posterior) probability of the hypotheses, then a Bayesian approach is needed in order to confirm which hypothesis is most likely given both the likelihood of the data and the prior probabilities of the hypotheses themselves (Jeffreys, 1961; Gelman et al., 2013).

\section{AUTHOR CONTRIBUTIONS}

JDP initiated and drafted the general commentary. DF and JP contributed theoretical background and feedback. All authors approved the final version of the manuscript for submission.
Neyman, J. (1955). The problem of inductive inference. Commun. Pure Appl. Math. 8, 13-45. doi: 10.1002/cpa.3160080103

Neyman, J., and Pearson, E. S. (1928). On the use and interpretation of certain test criteria for purposes of statistical inference: part I. Biometrika 20A, 175-240. doi: $10.2307 / 2331945$

Perezgonzalez, J. D. (2016). Commentary: how Bayes factors change scientific practice. Front. Psychol. 7:1504. doi: 10.3389/fpsyg.2016.01504

Perezgonzalez, J. D. (2017a). Commentary: the need for Bayesian hypothesis testing in psychological science. Front. Psychol. 8:1434. doi: 10.3389/fpsyg.2017.01434

Perezgonzalez, J. D. (2017b). Statistical Sensitiveness for the Behavioral Sciences. Available online at: https://osf.io/preprints/psyarxiv/qd3gu.

Rouder, J. N., Speckman, P. L., Sun, D., Morey, R. D., and Iverson, G. (2009). Bayesian t-tests for accepting and rejecting the null hypothesis. Psychon. Bull. Rev. 16, 225-237. doi: 10.3758/PBR.16.2.225

Conflict of Interest Statement: The authors declare that the research was conducted in the absence of any commercial or financial relationships that could be construed as a potential conflict of interest.

Copyright (C) 2017 Perezgonzalez, Frías-Navarro and Pascual-Llobell. This is an open-access article distributed under the terms of the Creative Commons Attribution License (CC BY). The use, distribution or reproduction in other forums is permitted, provided the original author(s) or licensor are credited and that the original publication in this journal is cited, in accordance with accepted academic practice. No use, distribution or reproduction is permitted which does not comply with these terms. 